\title{
Cobalt toxicity - an emerging clinical problem in patients with metal-on-metal hip prostheses?
}

\author{
Xinzhan Mao, Andrew A Wong and Ross W Crawford
}

\begin{abstract}
We report two Australian patients with possible cobalt toxicity related to metal-on-metal total hip replacements. Both patients were treated for osteoarthritis with a DePuy ASR (articular surface replacement) $X L$ Acetabular Hip System prosthesis, which contains cobalt and chromium, and which has recently been recalled from the market. (MJA 2011; 194: 649-651)
\end{abstract}

\section{Clinical records}

\section{Patient 1}

A 73-year-old woman presented to our orthopaedic clinic in February 2011 for follow-up of a right total hip replacement that had been performed 5 years previously because of osteoarthritis. At review, she had neurological symptoms, including cognitive decline, memory difficulties and depression, which had been present for 7 months since a cerebrovascular episode. She also had a continuous metal taste in her mouth and complained of severe headaches, anorexia and weight loss. She had mild groin pain but otherwise no symptoms related to her hip. X-rays showed a well fixed, well aligned implant, with mild osteopaenia around the acetabular component. Her serum cobalt level was $410 \mathrm{nmol} / \mathrm{L}$ (reference range, $0-20 \mathrm{nmol} / \mathrm{L}$ ) and chromium level was $240 \mathrm{nmol} / \mathrm{L}$ (reference range, $0-100 \mathrm{nmol} / \mathrm{L}$ ).

The cerebrovascular episode had occurred in July 2010, when the patient experienced symptoms consistent with a stroke: dizziness, disorientation, nausea, vomiting and being "off balance on the left side". She had particularly noted difficulty in remembering names and registering information (both written and aural), headaches and cerebellar signs (ataxia and dysdiadochokinesis). She had been admitted to the stroke unit and treated with ongoing clopidogrel. A computed tomography (CT) scan at this time showed a hypodensity in the right anterior commissure, although it could not be confirmed whether this represented a lacunar infarct or a perivascular space. CT angiogram, echocardiogram and thyroid function test results were all normal and she had no previous history of depression or dementia.

The patient's original hip replacement had been done in 2006 with an ASR (articular surface replacement) hip prosthesis (ASR XL Acetabular Hip System [DePuy Orthopaedics, Warsaw, Ind, USA]), comprising a largediameter metal (cobalt and chromium) cup with a large modular metal head on a titanium Corail stem (Box). A revision total hip replacement was performed in March 2011, principally because of her systemic symptoms and elevated cobalt and chromium levels. The ASR metal cup and head were removed and

the stem retained. Her acetabulum was revised with an all-polyethylene cemented cup and the head was changed to a ceramic one. At the time of surgery, $30 \mathrm{~mL}$ of turbid fluid was aspirated from the joint and debridement of metal stained tissue was undertaken. The concentration of cobalt in the joint fluid was $4218 \mathrm{nmol} / \mathrm{L}$ and chromium was $217000 \mathrm{nmol} / \mathrm{L}$. Cerebrospinal fluid (CSF) collected at surgery showed a cobalt level of $9 \mathrm{nmol} / \mathrm{L}$ and a chromium level of $13 \mathrm{nmol} / \mathrm{L}$ (no reference ranges for these in CSF), showing that the ions had crossed the blood-brain barrier.

At 8-week follow-up after the revision surgery, the patient felt much improved. She had regained a normal appetite and gained weight, the metallic taste in her mouth had gone, and she had less fatigue and greater energy. The hip pain had completely resolved and she was walking up to $2 \mathrm{~km}$ a day. Her serum cobalt level had reduced to $60 \mathrm{nmol} / \mathrm{L}$.

\section{Patient 2}

A 60-year-old male professor of engineering presented in January 2011 with systemic symptoms, for follow-up after a right total hip replacement with a DePuy ASR XL Acetabular Hip System prosthesis 4 years previously. He had no hip symp-

X-ray of Patient 1's right metal-onmetal articulation hip replacement, with well fixed cementless femoral and acetabular implant

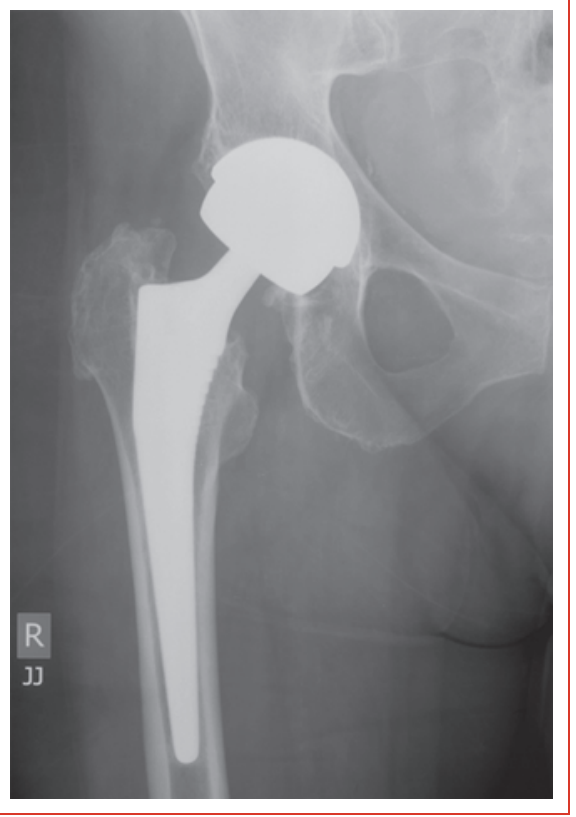
toms, but an x-ray showed quite marked bone loss around the acetabular component.

Before his hip replacement surgery, the patient had been working full time and enjoyed excellent general health, apart from pain and stiffness in his right hip secondary to osteoarthritis. Three years after the surgery, he developed symptoms that steadily increased in severity: painful muscle fatigue in all limbs associated with cramps in the hands and feet, particularly at night; dyspnoea and feeling faint when performing simple tasks; inability to climb a flight of stairs without needing to rest; and a decline in cognitive function (although this was not quantified). He particularly noted problems with remembering names and poor concentration. His previously stable hypertension had become uncontrolled and required additional medication.

The patient's serum cobalt level had been measured in September 2010 and found to be $185 \mathrm{nmol} / \mathrm{L}$, and subsequently remained consistently elevated at between $213 \mathrm{nmol} / \mathrm{L}$ and $258 \mathrm{nmol} / \mathrm{L}$. His chromium level was never elevated. 
In February 2011, the patient had a revision total hip replacement performed because of his systemic symptoms, in spite of having no hip symptoms. At revision surgery, the titanium stem was retained, and the metal head and cup were changed to ceramic and polyethylene versions, respectively. There was no metal debris or localised tissue reaction. Immediately before the revision surgery, the patient's serum cobalt level was $258 \mathrm{nmol} / \mathrm{L}$, with a normal level of chromium $(88 \mathrm{nmol} / \mathrm{L})$.

At 8-week follow-up after the revision surgery, the patient reported significant improvement in his energy levels and a decrease in muscle pains. He had significantly improved exercise tolerance and was able to walk without restriction. His serum cobalt level had fallen to $42 \mathrm{nmol} / \mathrm{L}$.

\section{Discussion}

Total hip replacement is generally a successful operation, with a long clinical history of good outcomes. Conventional total hip prostheses consist of a metal head that fits into a polyethylene cup. Concerns have been raised, particularly in younger patients, that the plastic cup suffers wear and tear with time and may require revision. In an attempt to decrease wear at the interface of the articulation, metal-on-metal bearings (Box), composed of cobalt and chromium, have gained widespread popularity and have been used extensively, particularly in the United States.

However, some of these metal-on-metal prostheses have not lived up to the promise of increased durability. The Australian National Joint Replacement Registry (NJRR) notes large differences in the performance of different types of metal-on-metal hip prostheses. An acceptable upper rate of failure of hip prostheses is considered to be below $1 \%$ per year, with the vast majority of implants studied by the NJRR falling well below this failure rate. ${ }^{1}$ The ASR prosthesis originally implanted in both patients reported here has recently been withdrawn from the market, after about 100000 were implanted worldwide. Its revision rate reported on the NJRR in 2010 was $6.4 \%$ at 3 years when inserted with a Corail stem and $10.9 \%$ at 5 years when inserted as a resurfacing. ${ }^{1}$ Updated guidance from the British Hip Society's 2011 conference noted a

higher than anticipated early failure rate [in large-diameter metal-on-metal hip replacements]. These range from [a] 21\% revision rate at 4 years (potentially rising to $35 \%$ if all currently known painful implants progress to revision) to $49 \%$ at 6 years for the ASR XL device. Other devices have a revision or impending revision rate of $12-15 \%$ at 5 years. $^{2}$

An additional problem with metal-on-metal bearings is that they release a variety of metal ions into local tissue and the general circulation, with chromium being the most widely reported of these. Increased cobalt levels have been reported to be associated with neurological ${ }^{3,4}$ (hand tremor, incoordination, cognitive decline, depression, vertigo, hearing loss and visual changes), cardiac (arrhythmias and cardiomyopathy) and endocrine ${ }^{5,6}$ symptoms. Symptoms of cobaltism have been previously described when cobalt was used to treat refractory anaemia in patients 40 years ago. ${ }^{7}$ The term "arthroprosthetic cobaltism" has been coined to describe these manifestations in patients with joint replacements. ${ }^{3}$

The direct effect of cobalt on cells has recently been explored. Exposure to cobalt ions was found to significantly inhibit osteoblast function by reducing alkaline phosphatase activity and calcium deposition, and to rapidly induce the secretion of proteins IL-8 and MCP-1 in primary human osteoblasts. ${ }^{8}$ This may have implications for bone ingrowth onto implants and osteolysis around the hip replacement. Other reported effects of elevated cobalt levels on cells include abnormal lymphocyte function, ${ }^{9,10}$ chemokine secretion $^{11}$ and ischaemic changes in rat brains. ${ }^{12} \mathrm{~A}$ relationship between symptoms and peak cobalt levels, or the length of exposure to cobalt, has not been established.

We believe our patients' symptoms were related to their elevated cobalt levels, resulting from cobalt leaching out of their hip prostheses. Both patients had metal-on-metal hip prostheses, and both patients' cobalt levels were reduced after removal of the metal-on-metal prosthesis. We are concerned that cobalt toxicity may be under-recognised, particularly if patients consult doctors who may not be aware of the details of the patient's hip replacement and the potential for release of cobalt into the circulation.

The British Hip Society recommends regular follow-up of patients with metal-on-metal hip replacements for at least 5 years and probably for the life of the prosthesis. ${ }^{2}$ Clinical manifestations of cobalt toxicity may occur many years after implantation of the prosthesis and appear to stay elevated over extended periods of time. ${ }^{13}$ Long-term exposure to cobalt may also be associated with cancer. ${ }^{14}$ Patients should therefore be followed up carefully, with specific questioning about alterations in neurological, cardiac, respiratory and endocrine function.

In the presence of persistently elevated metal ion levels and symptoms consistent with metal toxicity, once other causes have been excluded, revision hip replacement is the only method available to decrease the ion levels

\section{Acknowledgements}

We thank the patients for allowing us to publish details of their cases.

\section{Competing interests}

Ross Crawford has received consultancy fees and royalties from Stryker, a manufacturer of joint replacement prostheses.

\section{Author details}

Xinzhan Mao, MD, Associate Professor of Orthopaedics ${ }^{1}$ (formerly Visiting Fellow, Queensland University of Technology)

Andrew A Wong, MB BS, PhD, FRACP, Director, Stroke Unit ${ }^{2}$ Ross W Crawford, MB BS, DPhil(Oxon), FRACS(Orth), Professor of Orthopaedic Research ${ }^{3,4}$

1 Second Xiangya Hospital of Central South University, Changsha, Hunan, China.

2 Royal Brisbane and Women's Hospital, Brisbane, QLD.

3 Prince Charles Hospital, Brisbane, QLD.

4 School of Engineering Systems and Institute of Health and Biomedical Innovation, Queensland University of Technology, Brisbane, QLD.

Correspondence: r.crawford@qut.edu.au

\section{References}

1 Australian Orthopaedic Association National Joint Replacement Registry. Annual report 2010. Adelaide: AOA, 2010. http:// www.dmac.adelaide.edu.au/aoanjrr/documents/aoanjrrreport_2010.pdf (accessed May 2011).

2 Hodgkinson J, Skinner J, Kay P. Updated guidance on large diameter metal on metal bearing total hip replacements. London: British Hip Society, British Orthopaedic Association, National Joint Registry and Medicines and Healthcare products Regulatory Agency, 2011. http:// 
www.britishhipsociety.com/pdfs/BHS_MOM_THR.pdf (accessed May 2011).

3 Tower SS. Arthroprosthetic cobaltism: neurological and cardiac manifestations in two patients with metal-on-metal arthroplasty: a case report. J Bone Joint Surg Am 2010; 92: 2847-2851.

4 Rizzetti MC, Liberini P, Zarattini G, et al. Loss of sight and sound. Could it be the hip? Lancet 2009; 373: 1052.

5 Brock T, Stopford W. Bioaccessibility of metals in human health risk assessment: evaluating risk from exposure to cobalt compounds. J Environ Monit 2003; 5: 71N-76N.

6 Keegan GM, Learmonth ID, Case CP. Orthopaedic metals and their potential toxicity in the arthroplasty patient: a review of current knowledge and future strategies. J Bone Joint Surg Br 2007; 89: 567-573.

7 Schirrmacher UO. Case of cobalt poisoning. BMJ 1967; 1: 544-545.

8 Queally JM, Devitt BM, Butler JS, et al. Cobalt ions induce chemokine secretion in primary human osteoblasts. J Orthop Res 2009; 27: 855-864.

9 Hart AJ, Hester T, Sinclair K, et al. The association between metal ions from hip resurfacing and reduced T-cell counts. J Bone Joint Surg $\mathrm{Br}$ 2006; 88: 449-454.
10 Daou S, El Chemaly A, Christofilopoulos P, et al. The potential role of cobalt ions released from metal prosthesis on the inhibition of Hv1 proton channels and the decrease in Staphylococcus epidermidis killing by human neutrophils. Biomaterials 2011; 32: 1769-1777.

11 Devitt BM, Queally JM, Vioreanu M, et al. Cobalt ions induce chemokine secretion in a variety of systemic cell lines. Acta Orthop 2010; 81: 756-764.

12 Caltana L, Merelli A, Lazarowski A, Brusco A. Neuronal and glial alterations due to focal cortical hypoxia induced by direct cobalt chloride (CoCl2) brain injection. Neurotox Res 2009; 15: 348-358.

13 Engh CA Jr, MacDonald SJ, Sritulanondha S, et al. 2008 John Charnley award: metal ion levels after metal-on-metal total hip arthroplasty: a randomized trial. Clin Orthop Relat Res 2009; 467: 101-111.

14 International Agency for Research on Cancer. IARC monographs on the evaluation of carcinogenic risks to humans: volume 86 . Cobalt in hard metals and cobalt sulfate, gallium arsenide, indium phosphide and vanadium pentoxide. Lyon: IARC, 2006.

Provenance: Not commissioned; externally peer reviewed.

(Received 27 Mar 2011, accepted 19 May 2011) 